\title{
Simple annals of Money
}

\section{Harshad Dave}

Additional Genaral Maner (Retd.), Gujarat State Fertilizers and Chemicals Ltd. (GSFC), Vadodara, Gujarat, India.

\begin{abstract}
It is the most common notion with us that day by day purchasing power of our currency reduces on time line. It is a fact also. We find views and debate on the issue "Why and how it is so?" I also contemplated on it and I have tried to put my observations and out comes while pondering on the issue. On one part, it is tried to peep into the fetus of the money. On other side, it is tried to locate the foundation of money that determines the reliance of its purchasing power. The influence of parameters that determines the exchange ratio in any exchange process between commodity and money is also considered. It is revealed that human characteristics and overall health of social systems, efficient functioning of social institutions and ethical as well as moral values of members of the society projects grass root influence on determining the exchange value of money for any nation. It is to be noted that money has never a value, but it is evolved with human society where it has exchange value and an exchange value is never a value.
\end{abstract}

Key words: barter in promise, SP1, SP2, precious coins, supporting pillar.

JEL Classification: A13, A14, B21, F43, F50, I24, O12, P16, P26, P48, Z13.

(C) The Author, 2017. This article is published with open access at ARMG Publishing.

\section{Introduction}

It will be helpful to go back into the mankind history to understand the correct nature of "Money" that we use in our day to day life. Let us go back to primitive age of man where animal husbandry, agriculture knowhow, fishing, collection of jungle products, systematic gaming and establishment of primitive human society was still on horizon. We might learn that self-life survival and maintaining existence was the prime concern in day to day life of the inhabitants of that time. Let us go with a glancing on the path just passing through the tens of thousands of years of evolution that led to man to a primitive society that has developed above activities systematically to some extent and one will reasonably realize that it taught to man following vital lessons also,

[1] It is inevitable to live in a group if benefits of agriculture, animal husbandry, fishing, and collection of jungle products etc are to be exploited to support the life.

[2] It demanded a structure of living in a group where division of labour was inevitable. This ultimately got projected into socio economic formation of the time.

[3] It also compelled the members of such establishment to settle the issue of surpluses and shortages of commodities, produces, things and substances that are directly or indirectly connected to the activities of survival and making living of the men inhabiting in the society.

[4] It also introduced first and preliminary concepts of ownership and possession in conscious; otherwise they were in instinct only.

[5] It emerged with the necessity of compromise and introduction of trust, faith, and other terms of ethics also.

[6] It gave recognition of natural wealth that might indirectly prove to be vital for their easy survival, for example...grass land for their animals, rich fishing water- site, agriculture wise productive land and importance of natural water source for it, securing hold on jungle product etc.

[7] It gave introduction and performing nature of all the seasons throughout in a year, climatic conditions, propagating changes there in the climate and its influences on their day to day business and activities.

[8] The process of bartering and its inevitability to run the activities and day to day business within an establishment / society of the time.

For limiting our discussion within the concern of our subject matter only, though all the above points (and still more that are not mentioned here above) are listed, we shall discuss the last point "The process of bartering" to understand the real nature of money. Otherwise, learning from anatomy of above all the points reveals vital and influencing facts of economics. 
A summary of the existing literature. The topic of Money in economics has vital attention from scholars of economics. However, most of the writers / authors raised their stress on analyzing and investigating on purchasing power of money and its influencing parameters as well as other popular aspects. I did not find a systematic probing into the basic question "when and where money came into existence and investigation on the source of traces of its ancestral record". If one says story of evolution of money is no less old than that of human society, I shall surely agree with him and there is no doubt in it. It is interesting to make a logical link between present paper currency and ancient practice of barter against two commodities. Further to this, the most likely reasoning for a change from barter between two useful commodities to a barter between a commodity and a popularly valuable substance (precious metal). It is also interesting to investigate "why an interim precious metal needed while bartering?" as well as its consequential effect. The analysis of the parameters of influence that regulated and influenced the above process of evolution is no less important. While going through the present and past works on the above subject matter by various authors and scholars of economics, either it is not carried out or wherever it is carried out it did not find satisfactory... at least to me. Based on my efforts to find out the logical tale of source of money and its influencing parameters, I have tried to put some innovative findings emerged in my mind in this article. Only readers and time are the competent authority to judge if the same have some meaningful outcome that might help to the new generation of scholars in economics.

Process of Barter. A process of barter is influenced by more than one parameter. Also, there are various types of barters. When barter is carried out... where the commodities of the barter is physically ready for transfer of possession between bartering parties...the barter gets executed immediately on the agreement on exchange terms by both the parties. Now, as discussed above, the living in an establishment, in a group as a society, inflicts some liabilities and duties to be fulfilled by the members of the society to maintain the continuity (eternity) of living and incessant functioning of systems and institutions of the society. This serves to up-held the aim of that society.

In other words, it is mandatory to maintain the functioning of social system as a precondition; otherwise, the society will collapse and proceed towards reverse transformation to previous socio-economic formation or a retreat towards wild life again. Now, working in the society permitted (rather assigned) each individual to concentrate on a particular type of productive work within the frame work of his ability. Such works indirectly helps/supports those who are engaged in other productive activities in majority cases. The nature of such work assignment structure is a part of division of labour in a society. The division of labour might be understood in simple way as follow (However, it is discussed in a separate article on it).

When an individual maintains his survival and he is living in a jungle as an ape, he exercises his various abilities for the task of making living. If we prepare a list of the abilities, it might incorporate physical strength, climbing, running, ability to sustain seasonal climaxes, fighting and defensive ability etc. But, if one of them has an ability to play a tune on hollow bamboo bored by a wasp, it might attract some people. They might be interested by way of curiosity or might get impressed by the skill. But, the bamboo playing ability will never help him for making his living and maintaining his survival by managing substances competent to satisfy his needs. It is so because the skill or ability to play on a bamboo is not recognized by the system of nature prevailing there for maintaining existence.

If we closely analyze the primitive social system and its functioning, it is very clear that primitive farming, animal husbandry, collection of jungle products, fishing in bulk quantity in systematic way became plausible only if the mass of the people there work in synchronization. The system runs with various types of works to be carried out to support the other works and activities. For example, bulk fishing was possible if the persons going for fishing have fishing net, rafter to navigate to the area of water where such lucrative fishing yield is possible. Also, they should also have dexterity, experience and skill of the fishing task as well as practice to work in coordination with more than one person. It is not possible for the above fishing team to knit the net and make the rafter for the navigation at the same time bearing responsibility to go for fishing. Even if they might have capability to do it (fishing net and rafter making), it becomes the part of others job who finds more effective hand on knitting rather than on fishing at deep water site. The ready net and rafter as well as working in group made the bulk fishing yield a reality. It provided a share for survival to all those who did not go to fishing but worked to support the same. Though this activity seems to be a simple phenomenon, it has a vital change there in it.

Some people that survive in the system have ability to make and repair rafter, tools and devices for jungle 
product collection or to knit a net. Their capabilities to maintain their survival in jungle or in surrounding nature on their own is not tested since their birth or attempts were made to test their competency for such works, but, they could not perform the work satisfactorily there. Those who were having competency for such works, might fairly manage to secure an adequate quantity of such products, provided they are given support by relieving them from other works like making rafter, knitting net for fishing, making hand tools and devices to collect jungle products etc. The people who could not perform on front line (in this case fishing at water front), but found fit for making supportive devices as above, they were given share out of yield gain by the people working on front line in field. It simply establishes that these people survive on their skill of making rafts and knitting the net etc. It is one of the prime differences between human society and wild life society in nature. The nature recognizes various abilities mandatory for the survival of a man at a place, and weakness in or absence of such abilities is a threat of survival of the man. It is a fact, human society and its systems offer an opportunity to a man for his survival on such an ability that is not recognized by the nature. [NB: Our subject matter of this article is "Money" and our discussion is not diverted at present but it is essential to grasp background of its origin].

But, the system of the society has maintained his survival on the same ability that is not recognized by the nature. Here also, example of knitting a fishing-net and making a raft as above are not recognized by nature for maintaining survival but the social system recognizes them for the same.

It is also true that living in a human society offers more subjects of survival (i.e. means of subsistence), in variety and in quantity to a man compare to that of an individual who survives on his own in a jungle (or nature) and gets them in his day to day life. Further to this, an individual living in a society needs more means of subsistence than an individual in nature or jungle to maintain his survival. For example, a carpenter needs all his tools for his work that earns him his survival.

It is the pre-condition that is required to be fulfilled. That is...the structure of the society should provide these means to each individual. When each individual gets such means, and works within division of labour, he might produce such a quantity out of his working in a group that the produced quantity might not be necessarily required in full for their (fishing group) own consumption, but also remains adequately in excess after a share of the fishing group. For example, a fishermen group in a society might catch such a bulk quantity of fish with the help of a raft and fishing net that the quantity might be much excess to their requirement of all members of the group. Even the quantity might remain surplus also after consumption by all those who helped him (may be family members) to make and maintain his raft and fishing net.

The surplus fish is the commodity for barter. Here the barter is necessary, because the fisherman and his companions cannot survive only on fish alone. They all need other supportive food, also, minimum clothe, shelter etc. Now a man maintaining cattle, hog and poultry may be with surplus milk, meat and eggs, but he needs fish as a supplementary to his food. Now, when the party with surplus fish gets milk in exchange with the party with surplus milk, the process of barter is an inevitable need to maintain the functioning of the society, otherwise, existence of society might get threatened. This is the preliminary concept of barter initially surfaced out in the human society. The word barter itself has wide meaning today. A book might be written to explain its types, nature and influence on social system at different stages of evolution of mankind. However, we use the same word for primitive social system that is described above.

The barter of surpluses was most simple one. Its inevitability for the smooth functioning of the prevailing social system of the time there at the place was untold and unwritten knowledge of the inhabitant of the society. There might be events of stealing, grabbing and depriving by force under threat. But, people of the society might have learned that such events might lead the system to a collapse. This situation emerged with a requirement of ruling of the social system by some people. The necessity to comply some established rules and practices emerged. Today we see the same ruling through judiciary and police force for keeping law and order in commerce and business transactions as well as laws and guideline for trouble free operation of social system. So, leaving such casual events of outlaw, barter was the most popular and acceptable way of settling issues of surpluses against needs of varieties It is fair to accept that the population there in the society was maintaining their survival on the established and prevailing productive system. However, the surviving population at one place had following threats on their existence.

- If the resources of their productive system get exhausted due to natural force majors or with any reasons like mass population destruction in epidemic, natural disaster etc. 
- If a mass of people of other establishment at different places migrate to the same place where the society/establishment in discussion is habiting (living), and in the event, conflict of interest turns into fight between the two people.

- Shortage of essentials of survival due to internal population growths originates internal conflict posing risk of paralyzing the prevailing social system.

Limiting our discussion to our subject matter only, let us look into the third point only i. e. Threat due to internal population growth.

As population increases in the establishment, shortage of means of survival emerges. The situation leads to a demand of further exploitation of the resources in use or exploring new resources. Unfortunately getting success in above remedy is not certain, while need of means of survival of surplus population is a persistent demand of every day. The situation introduces tension in the every social relation/business and activities within the establishment. The effect of tension projects its influence on the process of barter also. It is logical to believe that the tension in barter led men to audit their need and at the same time cost of the commodity in their hand for the barter. Whenever and wherever the success - either by exploring further new sources of survival or inventing means of exploiting the same on hand with higher rate - was reached, the realization of the success (for its fruitful exploitation) also brought demand of updated social activities and relations among the social systems to support the new productive environment.

This new structure of internal social relations, business and activities brought influence on bartering process also. This updating in social structure brought new means of survival along with many other things of vital importance for the survival of population there in the establishment. The barter became more complicated and frequent in numbers* compare to that of past in the society.

[in numbers* means - let us consider a habitation of one socio economic formation where people makes their living on gaming, fishing with net and collecting jungle products. If we count the number of commodity exchanges (barter) that takes place every day, and it counts... say one hundred per day. Let us again survey the same count after some years (few hundred or more), when the social system in the same habitation is upgraded to the level of agriculture activities with the help of horse, various facilities and conveniences available with the help of inventions and discoveries and proportionate development in other social system and activities, our fresh survey for number of barters taking place everyday might count in a thousand or more commodity exchanges (barter) per day in the habitation.

We all know that varieties of various products with different characteristics are produced by the members of the society. Initially, barters might be among milk, fish, honey, combustible wood, leather, games, clay pots or pat animals etc. Now demand of more exploitation of resources through productive system led to development in the social activities as above to accrue benefits using knowledge of experience, discoveries and inventions. The growth and upgrading in new social system ultimately increased its (barter) frequency and numbers as well as exchange among many other (varieties) thing/product also. Here in new system, now, the bartering was not only among the above listed items, but the list was enriched with bow and arrows, fishing net and rafts, accessories for guarding fence to the safety of pat animals, lasso and honey collecting pots, carts, plough, and other accessories for farming activities, cages for bird, ropes and pulleys, and many other tools for farming and manufacturing of devices, facilities and conveniences to increase the productivity for multiple things.

However, again holding the region of our discussion within the frame work of our subject matter "Money", let us pip into the changes and influence on barter due to this social up gradation. One very important upgrading in barter system had to be introduced and that is "Barter in promise".

Barter in promise - "the fetus of money". One will agree; the every social system exists under full influence of climate, seasons, and environmental-changes and with natural favors or calamities. Uncertainty and eternal change are a part of life. Our every confirmed program and planning schedules are always with many invisible and untold "if... but and provided". The subject uncertainties and changes have an influence on the process of barter. Also, the products or substances that are to be exchanged in barter might have different characteristics. Some products like meat, fish and milk has perishable character with very short time life span. Corn, honey, onion, potatoes etc has comparatively longer time before getting perished. While products like plough, rope lasso and raft etc has longer life span. The parties in barter might have any of the substance on hand irrespective of its life span in the process of exchange. The influence of life span on the process of barter 
has a dominating effect if the product is going to get perished within short time.

Further to this, barter can never remain immune from human feelings, intentions, and character. The reliability of anticipated realization from the substance, that a party in barter is going to get under his command, ultimately depends on the trust of either party on the opposite party. There are innumerable events that emerge from so many situational reasons where either party has to either trust the opposite party or barterer process ceases and get terminated without materializing. It might happen that a person who has a poultry farm at his home needs staple corns for his daily food support as one of the prime ingredient. At the same time, a farmer needs eggs and chicken every day or frequently for his food support. The corn is sowed and may take few months to get it finally at home for exchange. The poultry person continues to supply eggs and chicken to the farmer till the staple corns ripped and reached to farmer's home for exchange.

Here exchange of staple corns exactly against the chicken and eggs cannot be realized because life span of chicken and eggs is very short, also, it is consumed in limited quantity but its availability should be every day in fresh condition. The production system of chicken and egg has regulation and natural control and produces it every day in approximate required quantity only. While life span of staple corns is comparatively longer one but it is produced in bulk quantity. Its availability in production system is once in a season. However, it is a practice to consume it every day in required quantity. We get sufficient life span in the staple corns after storing it in bulk quantity.

The barter between two parties, for chicken and egg against staple corns, has to be done with a condition. Here one party might have to hand over either side commodity (chicken and egg), under promise of supply of other commodity (staple corn) in future from opposite party. Here it was a promise to supply staple corns to the poultry man against his advanced supply of eggs and chicken. There are innumerable barters that have to be carried out with a time leg in exchanges between two commodities. The exchange of either side commodity in promise of supply of other side commodity in the barter became day to day requirement to keep the upgraded social system alive. Failing in it risked the collapse of upgraded production system. The failure ultimately would risk survival of that part of population that could survive only after new upgraded production system was prevailed. The above barter might be distinguished with a name...barter in promise.

The "Barter in promise" was not optional but inevitable. Once the barter in promise founded as a popular system in day to day life of the social transactions, events of breach of promise also started to emerge. There were fair chances of events and happenings of breach of promise. At the same time, the inevitability to carry out "barter in promise" and its frequent breaching by either party resulted into de-trust on it (on barter in promise). The ultimate result of this dismay created a situation that loomed a threat of collapse of upgraded production system in the society that would ultimately result into destruction of population in proportion, if prevailing system might collapse. A hunt of remedy to this situation ultimately gave a birth of concept of interim assurance till the exchange of pending commodity is not realized. It was the felt necessity of time to tender some assurance that will set the mind of the party in "barter in promise" to release the possession of his commodity against the commodity assured in future by the second party.

There might be more than one method for getting the above assurance to realize the commodity exercising "barter in promise" on single side transaction. The process of application of such remedies might have taken several hundred years or more, but ultimately the process of "barter in promise" could be survived till date and proved to be most versatile in public acceptance. Out of various methods and practices prevailing at that time to secure "barter in promise" safe, the method of holding a substance or thing of assured value - that sprouted trust in the minds of most of the men constituting that society - became the popular one. Here I admit that there are other reasons also that supported the barter in promise. For example, a surplus substance- $A$ with one party might be handed over to other party against promise of return of a substance- $B$ that the recipient party is likely to get under his command after a length of time from other sources. However, presently the handing over of the substance- $A$ is essential to get the substance- $B$. It was not always conveniently feasible that both the parties in barter might be with the command of their substance/s in barter. There might prevail interim handing over of substance- $C$, on temporary base till the second party manages the required substance$B$ ready to hand over with return of interim substance- $C$ (that had been kept as bail by first party).

Precious metals are one of the substances that had won trust of people (even today) with an assured evaluation of the same by any member of the society baring some exceptional or rare cases. Also, the precious metals like gold and silver are non-perishable for a very long time. Precious metal of the time proved to be a trustworthy substance with reliable exchange value. That too, the assurance was not the product of any person 
or social group, but it has a foundation with grass roots in a history of thousands of years. This is discussed in detail in my article "Views on Value of Gold". The use of precious metal or a substance of assured value in barter in promise is the fetus of money that we use today. The use of precious metal while entering barter in promise established as time passed and that might have taken more than few hundred years or more. It might be reviewed in short as follow.

The use of precious metal for executing barter in promise demanded segregation to quantify the precious metal with some regular form and mass of it. So the requirement of precious metal segregated into some uniform small quantity of it, its molding in some regular form or shape and assurance of its purity became every day's demand. The small quantity, in more or less uniform shape and size with its purity certainly helped to enhance the reliability as well as versatility of its use in the barter in promise.

It is human nature that always finds for every opportunity to realize his desire. Such opportunity might sprout from even unethical means and methods also. Some people might not hesitate to adopt such unethical ways and means also to fulfill his want. Here also, the method of tendering precious metal pieces resolved the problem of realizing possession of either side commodity against barter in promise but at the same time it opened doors for other troubles to make entry. There were ample chances that events of cheating might surface out while carrying out barter in promise with the help of precious metal pieces. The precious metal pieces, offered against barter in promise, might be proved to be either of inferior quality or completely spurious one.

Again, large frequency of happenings of the events of cheating in the barter in promise created serious disturbances in the day to day business activities of the society. Once upon a time events of breach of trust threatened the regular performance of social systems, man resolved it with the help of precious metal. Now, cheating in precious metal pieces emerged with. These again surfaced out with quarrels and dispute as well as retaliatory actions and counter actions. That ultimately proved to be a threat to the society itself.

The up gradation in barter process was not the demand or precondition as free choice of the new productive system. But, it was compelled by upgraded social structure in such a status that, it only can support the new productive system. "The development in ruling structure", "need to defend the society and its functional net work", "mandatory necessity to keeping law and order in the society" etc were the main aspects of the upgraded social system. Here up gradation in barter system as above was also a part of it. As the events of cheating in barter in promise created trouble in day to day social business and activities, being a concern of the ruling group, they might introduce pieces of precious metal with a symbol of their rule on it and with some regular shape, also with comparatively uniform weight depending upon development of that society at the time. The method of accepting precious metal pieces from parties other than those coins endorsed by ruler of the society while carrying out barter in promise got diminished in a span of time to escape from cheating. This was for the day to day use in the barter and other social business, activities. This might be designated as an infant age of money.

As ruling authority had responsibility to keep the functioning of the social system alive, it (ruling authority) controlled the quality and other parameters of the precious metal pieces marked/produced by the ruling system. The manufacturing accuracy in above design of precious metal pieces by ruling authority depended on the development of the social system that they represented. Such coins of precious metal offered some trust in the people residing in the society while accepting the same during barter in promise. Here, I specifically point out that the trust of the people, on the precious metal coins produced by a ruling authority of the social system, might be separated in two parts.

Trust-1 is the trust of people on exchange value of gold and that trust has foundation of thousands of years.

Trust-2, the second part, is that part of the trust where people of the society trust the reliability of the social system, and ruler of the system as far as its purity, weight etc are concerned. Thus, the coins of precious metals manufactured by the rulers of the system proved successful to get rid of cheating issues while carrying out barter in promise in the society by the people. Of course, it would have taken hundreds of years or more to reach at this stage. As the use of coins of precious metal became more popular in barter in promise and during other social business activities, its use might spread even outside the society, with other establishments also. Here also, outside people's trust on the social system that gets represented by the coins was prime one. While as outside people's trust on exchange value of gold is equally strong as with the people of the social system of the precious metal coins, it helped to carry out barter in promise with the people from other habitation also, and this indirectly confirmed the trust of outside people on the rulers of the society of which coins belong to. 
Before we proceed to discuss on aspects of coins of precious metal and then after about money, it is necessary to discuss one typical aspect of developing society, as it has vital influence on the subject matter we discuss here.

Typical aspect of the human society. To whom we say social development is mostly nothing but eternal process of finding remedies to secure survival of surplus population. Of course, if we take up the activities of an individual man of a society we shall learn, in most of the cases, that his all the activities are targeted towards making living and maintaining survival, satisfying his needs from various zones (for zones see my article on "Need"). However, his all the investment and expending of resources just to satisfy his all possible needs partly satisfy the invisible problem of surplus population. This process is a set of different activities being carried out by various people for their own target, ambition, purpose or for self motivation. The process of these activities is just like Brownian-Movement of water molecules in a standstill pot.

There are various types of men in the society and they are with different abilities. At the same time, it is the nature of man that his mind always has some ambitions. The ambitions might be from different fields and of various types. But, a man without single ambition must be in image only. Not only that, but he always remains anxious to fulfill his ambitions as and when he gets suitable opportunity. Further to this, he is ready to put his every possible effort and devote earnings on deal to fulfill his ambitions.

Every person born in the society has his own nature, heritage, abilities, choice etc. Some of them are intellectually more powerful and curios to know facts and reality. They have ability and initiatives for contemplating on challenging issue and unresolved problems. The intelligent and curious men make discoveries and inventions and add to knowledge. However, it is not always their (people who makes discoveries and inventions) aim to establish how and where such inventions and discoveries might be helpful to mankind for solving their social problems. The discoveries and inventions are the product of their curiosity, intellectual experience and ambitious nature in the field. They are scientists of different fields and their ambitious curiosity reveals the facts of science and nature.

NB: Generally, we all distinguish between discovery and invention. We all are aware of the difference between two. However, if any one sharply scrutinizes any invention, he will realize that invention is nothing but intelligently selected set of various discoveries only along with material support. When we combine various materials along with use of knowledge of different principles, rules and laws discovered and known to us in such a systematic way that combination of above all constitutes a set of particular device that yields an anticipated service or out come from the constituted set up, we name it a new invention. Otherwise, it (every invention) is a classically and intellectually selected set of discoveries along with material support.

Coming back to our talk. Other ambitious people turn them (discoveries and inventions) into practical use to accrue benefits out of the same to sort out problems of the society. Any human society is having its own systems and institutions depending upon socio economic formation of the time. This constitution of human society is different than that of wild life and it is a fact. With this fact, it is also true that the methods and means of surplus population destruction in both the system are different. Every person in human society is attached with some people in close relations like parents, brother and sister.

Different types of struggle for survival prevail in human society. Mostly, each person gets help or protection to the extent possible from his above close relatives to escape from the struggle of survival. Also, ethical feelings in the heart of some other people support the survival in the struggle. I think, we do not see such charity in wild life system. Wild life methods for destructing surplus population in any type of struggle are simple and plain. But, we always see parents to secure making of living of their children in human society. The persistent demand of the society to make arrangement for the survival of surplus population induces the activities that ensure accruing benefits from their knowledge, inventions and discoveries and experience that ultimately ensures additional means of survival for the surplus population.

This spontaneous demand of settling surplus population creates a social flux of an invisible force to get them (efforts - to find the applicability of inventions and discoveries done by others) channelized to sort out problem of survival of surplus population. This process - making inventions, discoveries by some people and finding its applicability on natural resources to earn benefits of the same in the interest of mankind by other people prevailed right from the initiation of the human society. However, during primitive stage it was much diluted one while as after some development of society, mostly in the field of agriculture, animal husbandry, fishing, use and control of fire, use of pat animals in agriculture, the above process became more distinct. 
Subsequently, social structure, types as well as varieties of activities were considerably increased in the above developed society compare to most primitive human establishment. During the initial stage of developing society, barter was between two i. e. producers as well as consumers and it was for substances of some direct value to them. Later on, when inventions and discoveries were to be used to support the social system, the numbers of activities in the society multiplied. This resulted into large numbers of barters to be carried out for multiple varieties of substances and things involved in it. At the same time, the numbers of substances and things in day to day use in varieties and quantities also increased substantially. Also, there prevailed a demand of services of different types and a system of hiring services also emerged with this development; otherwise, it was not a popular practice in previous socioeconomic formation. The hiring of services has a concern to the subject matter in discussion on money. The use of precious metal pieces generally used in barter in promise became popular to reward against the hired services also.

If we go to very primitive society, the list of various items generally used in the society for making living might be counted on fingers. As the man encountered difficulties in his life he searched for remedy. The curiosity of some of the intellectual people there in the society might find out remedy for the same with advance knowledge and experience. Some other people applied above achievements in a way to sort out remedy for some popular social problems of the time. These problems might be pertaining to defend from wild animals and threat to their productive and supporting resources. Also, necessity for storage, transport, preservation, and requirement to replenish shortage of food against population growth and other such requirements created an appeal to settle them. Remedy to satisfy the above demands attracted involvement of various things like tools, devices, erected facilities, weapons, set ups, necessity of communication, igniting and regulating fire etc. The services required from the above things/devices demanded special material with particular characteristics. These all needed further involvement and use of various materials otherwise they were not in use. The new discoveries and inventions satisfied these demands. This was nothing but an upgraded social system that had capacity to produce more with the help of the upgraded system, also to store and protect them.

Ultimately this up gradation led to such a formation of society that had comparatively longer list of various materials and substances used in the social system. Now that could not be counted on fingers.

It is also true that varieties of day to day activities and social business also increased proportionately. The demand and use of precious metal coins also became more and more versatile and popular in the society. Also, it did not remain within the society. But, it extended between the two such societies also to maintain and retain the respective transactions and activities between the societies. The process of population growth, shortage of means of subsistence due to the growth, problem of survival of surplus population, demand of further productivity for their survival and its remedy through further exploitation of natural resources with the help of up graded tools, devices, facilities etc based on inventions and discoveries became an incessant process in human society from primitive to today's advance society. The everyday activities and social business became more and more complex and populated. The precious metal coins supported and authorized by the ruling social system remained in use as a life line of all the transactions of social systems.

The above aspect of human society is typical one and vital for understanding the character of money as, now, use of coins of precious metal did not remain limiting to barter in promise only, but the same were paid for services, labors, while transferring of ownership of cattle, land, wood, appliances for protection from weather, weapons and devices for gaming, weapons for protection and defense, devices to store and preserve etc. The versatile use of precious metal coins was in support to the performing of various social systems at such an extent that any interruption in the use of the coins might retard the social system working at an extent that might risk collapse of the functioning of network of the society. Here above, we discussed the proliferation of precious metal coins in the society and system's dependency on the coins.

Let us go back again to the character of precious metal coins and its use in barter in promise and other business/activities of the society to understand the real concept of money.

The two supporting pillars of the precious metal coins in use. It is necessary to look into the detail constitution of some important aspects of the coins of precious metal that were used for barter in promise and other social business and activities as discussed above. The simple barter was safe as exchange of commodities in agreement were ready with both the parties in deal for handing over. Otherwise, barter in promise might be partly realized on completion of said exchange of commodity on either side, and balance part of exchange of commodity of other side was kept under promise in future. There is always a looming threat of breach in 
completion of promised part. The precious metal coins authenticated by the ruling group of people (or system) rendered a service where handing over of precious metal coins secured the interest of both the parties in deal. This means the party, receiving the precious metal coins against delivery of his commodity, was rested assured to realize his need of required commodity in exchange with the same coins at any time. Though it seems simple one it is critical also. When one party receives and accepts the precious metal coins against handing over of commodity under his possession, he trusts the coins as above. The origin of the subject trust rests on the assurance which he gained empirically that the same coins would surely find the same recognition from other people of the society with whom he might have to deal with. Now, if you sharply analyze the foundation of above subject trust, you will agree that the trust is supported by two pillars.

1. One pillar is his faith in precious metal that has won a status and value in the minds of all most all the people of the society. This faith assures him about the return/exchange value of the coins of precious metal. The trust for assured exchange value of the precious metal (here gold) is founded on thousands of years' experience. [Please read my article "Views on Value of gold".

We shall address this first supporting pillar as SP1 in short form onwards to this article.

2. Second supporting pillar is assurance and authentication given by the ruling people or social system for the quality and quantity assurance in the metal coins. We shall address this second supporting pillar onwards to this article in short form as SP2.

If we sharply analyze, it is clear that SP1 constitutes support to substantially larger part of the trust on the coins of precious metal compare to that of SP2. This bifurcation might be to the tune of $90 \%$ by SP1 while $10 \%$ by SP2. It means, a man in a society with a precious metal coin is assured with an esteemed trust of its exchange value and that trust is constituted by SP1 (90\%) and SP2 (10\%) in above proportion.

Now as discussed above, incessant process of social development brought following important major changes,

- The occupied area of the society increased at the same time inhabited area also increased with population growth.

- New materials were discovered for various uses. Also, new characteristics were also discovered in the materials that were already in use. Further to this, various characteristics were developed by processing for making chemical compositions, mixing and amalgamating different materials.

- Processing on available materials to make it useful was carried out in bulk. System of production of food in bulk quantity was adopted.

- Various means and methods of bulk transportation were commissioned.

- Use of animal labour replaced human labour; also, some other services by animals were also availed.

- New energy resources, developed and set ups for conversion of one type of energy to other types of energy, were installed.

- Powerful devices to extract raw material in bulk quantity and to store the same were developed.

- Poultry farming, fishing with net and boat, animal husbandry, use of means and devices to acquire and collect jungle products added the food production facility.

- Producing weapons and skill for fighting and defense facilities were developed.

- Improvement in shelter and home-making and arrangement for comfort were introduced. Facilities for storage and technique for preservation of commodity were developed.

- Communication methods, travelling facilities, conveyance and transportation were set up.

- Tools and devices were invented and employed successfully in the society for carrying out various activities.

Above changes developed the society in which material transaction, social business and activities, huge numbers of day to day barters, various types of services on chargeable basis, establishment of various types of institutions essential for regulating and control of social business activities along with working of administration system substantially etc increased the use of precious metal coins in above social system. The growth of population and overflowing various commodities, and a healthy social network provided a good avenue to various activities as above. This demanded sufficient quantity of coins of precious metal to cope 
increased frequencies of numbers of barters to support the demand of developed human society. When the prestige and reliability of a social system was at higher level and it retained also for a longer time, the rulers of the social system introduced coins of metals bearing inferior exchange value like silver, copper bronze etc.

The adoption of inferior metal coins in barter in the social system did continue with all the social business activities along with the barters. But there was an invisible serious shift in the status of SP1 and SP2. As the constitution of metal coins is now not of precious metal, but of inferior metal, the supporting pillars SP1 and SP2 of the trust on the coins had then become with different share in the supporting proportion. Previously it was 90:10 respectively while as now it has shifted to 1:99. Once upon a time, SP1 enjoyed $90 \%$ share in the above discussed trust in the process of barter. Now the same supporting pillar SP1 is enjoying only $1 \%$ share as the coins are manufactured from very inferior metal. The total quantum of trust is same but now SP2 enjoyed $99 \%$ trust in the social transactions.

Here is the game. The share of the trust by SP1 is founded on history and facts as shown in the article "Views on Value of Gold", and it was $90 \%$ when used for the social business activities and barter in promise, while assurance of ruling system for quality and quantity occupied $10 \%$ only. But, now in the advance social system using coins of inferior metal for the same social business activities and barter in promise, the share of the trust by SP 1 might be $1 \%$ (rather less than $1 \%$ as the currencies are from paper only) while as that of SP2 occupied $99 \%$.

Further to this, the trust shared by SP1 was representing the faith and assurance to get the justified quantity of required commodity against exchange with the precious metal coins. While as that of SP2 represents the faith in social system, its reliability and trust worthiness for the quality and quantity of the coin metal, stability of the ruling system sustainable capacity against all possible evens and odds etc.

With the above discussed shifting, the total faith of reward of commodity against metal coins now shifted to SP2 as the metal now used is of inferior quality and this might not attract any people of the society to exchange commodity against it as it was being carried out in the case of coins of precious metal. But now the trust in getting exchange value is ultimately shifted from "precious metal" to "trustworthiness of the social system".

The shift of share in the trust as above from SP1 to SP2 is the most important and major influencing parameter in the behavior study of today's money. The use of inferior metal coins in social business activities and barter in promise was the young age of money. Inventions and discoveries were systematized through research centers. Use of outcome of research centers and random inventions / discoveries, development of various type of human skills, education and experience, upgraded the social system with new dimensions. Coins were replaced by paper currency (the paper coins). SP2 became the sole occupier of the trust in social business activities and economic transactions that replaced barter. Now reward against currency in terms of required commodity totally relied on single support SP2. Ultimately, assurance of reward against paper currency was and is founded on the competency, reliability, efficiency and health of the social system and its ruling body or nation as SP2 is the only supporting pillar of the trust that we discussed.

Before we go for a conclusion, I should remind the readers some facts. Always remember that money has exchange value right from its fetus. The determination of exchange value in any exchange process is influenced by many parameters (some 20 parameters) that are listed here bellow,

\section{The list of the parameters:}

1. Quantum of labour and cost sustained on the commodities in their possession.

2. Lack of adequate knowledge about commodity in exchange process.

3. Potential of affinity (propensity) in either party to satisfy the subject need.

4. Possibility to sustain without subject exchange.

5 . Knowledge about alternate source of availability of the commodities in exchange process.

6. Vision for future prediction.

7. An exchange for recovery purpose.

8. An exchange under acquaintance, relation and under-impression.

9. Process of exchange where on either side more than one party negotiate.

10. An exchange where either or both parties have poor recognition of the quality/specifications of the commodities in exchange.

11. An exchange under adverse or favorable circumstances and helplessness.

12. An exchange carried out in artificial environment. 
13. Lack of adequate information with either or both parties.

14. Influence of misleading propaganda and rumor on exchange process.

15. Exchange under threat and pressure.

16. Exchange with a purpose to oblige or for ethical consideration etc.

17. Exchange with a purpose to acknowledge an appreciation by either party.

18. Different hidden intentions to be upheld through the process of exchange.

19. Process of exchange carried out under instigation by others:

20. Process of exchange carried out just for showmanship.

If we go through the above parameters carefully, we shall realize that there are fare chances that an exchange value for a commodity might return different for the same commodity at one place and at same time in two independent occasions of exchange. Moreover, looking to the parameters of influence as above, it is clear that there are many parameters that are under influence of human characteristics. When no man is equal in characteristics, naturally, the potential of influence of the same will differ. The difference in the influencing potential reflects in exchange value. Ultimately, I want the reader to realize why a sum of money does not have stable or uniform exchange value (here purchasing power). Of course, rulers of the society put regulating curb on the above parameters by enacting various laws and standards, but its effectiveness is always an issue. As I do not want to divert from the line of discussion, I just point out that on one side the exchange power of money gets eroded by the human characteristics adverse to ethical values. On other side, the foundation of money that was originally on SP1 is now shifted to SP2 as discussed in this article. Now SP2 itself is totally dependent on the health of social net work only. Ultimately purchasing power of money gets shifted on the overall health of the society, its net work, systems functioning and efficiency of working of its institutions.

\section{Conclusion}

Money (currency) of any nation holds its reliability on following major aspects of the society of the nation.

1. Natural resources available to the nation and ability of the people of the nation to exploit, control, regulate and protect them.

2. Peoples education and alertness, keen and effective interest in the ruling of the nation, and people's ability/competency to keep vigil and audit the functioning of the social system, people's high moral and positive ethical values in their living, people's zeal to maintaining high self-discipline in day to day life.

3. Efficient working of the people, honesty, and determination for maintaining high social value, keeping all the public institutions with efficient, punctual and clean working, people's preparedness to offer devotion and sacrifice on demand for the sake of maintaining high social and moral values.

4. Powerful will power of the people, immune from social dirt like corruption, gambling, drug addiction, and other anti social activities.

5. Hard and efficient working with excellent productivities, controlled population growth, devotional determination for high ethical values.

6. Ability and preparedness to repel any outside threat to the nation, with loyalty to the nation.

7. When the above aspects of the society become powerful the SP2 becomes equally reliable and reliability of SP2 only can provide true value (exchange value) of money in place of SP1. As the above aspects of the society go weaker and weaker, the reliability of SP2 gets liquidated automatically and money loses its exchange value.

\section{References}

1. Carl Menger. (2007). Principles of Economics. Ludwig von Mises Institute, Auburn, Alabama, Forwarded by Peter G. Klein. Reprinted. Chapter-VIII Theory of Money, 257-280.

2. Henry George. The science of Political Economy abridged by Lindy Davies. Part-V Money: the Medium of Exchange and Measure of Value. Retrieved from: http://www.politicaleconomy. org/speV 1.htm

3. Adam Smith.mWealth of Nation, Chapter IV. Of the Origin and Use of Money, Chapter V, Of The Real and Nominal Price of Commodities, or Of Their Price in labour, and Their Price in Money, 31-44.

David Ricardo. The Works and Correspondence of David Recardo. Edited by Piero Sraffa with collaboration of M H Dobb, Volume I. On the Principle of Political Economy and Taxation, Chapter XXVII. On Currency and Bank, 352-372. 
4. Alla Sheptun. Philosophy of Money. Retrieved from: https://www.bu.edu/wcp/ Papers/Econ/EconShep.htm 5. Kenneth E. (2004). Boulding, General systems theory. The skeleton of science. E:CO Special Double, 6(12), 127-139.

6. Weber, Max. Economy and Society. Retrieved from: https://archive.org/stream/ MaxWeberEconomyAndSociety/MaxWeberEconomyAndSociety_djvu.txt

7. Man Karlfried Durkheim. (1988). Hara the Vital Centre of Man, 1-109. Retrieved from: https://terebess.hu/zen/ mesterek/Hara.pdf

8. Mackellar, J. (2013). Participant observation at events: theory, practice and potential. International Journal of Event and Festival Management, 1-18.

9. Menger, C. (2007). Principles of Economics. Ludwig von Mises Institute, Auburn, Ala, USA. Retrieved from: http://austrian-library.s3-website-us-east-1.amazonaws.com/books/ Carl\%20Menger/Principles\%20of $\% 20$ Economics.html

10. Whitaker, J. (2001). Henry George, John Stuart Mill and Adam Smith. The American Journal of Economics and Sociology, 11-24. 